IRA-International Journal of Education \& Multidisciplinary Studies ISSN 2455-2526; Vol.07, Issue 02 (2017)

Pg. no. $109-116$

Institute of Research Advances

http://research-advances.org/index.php/IJEMS

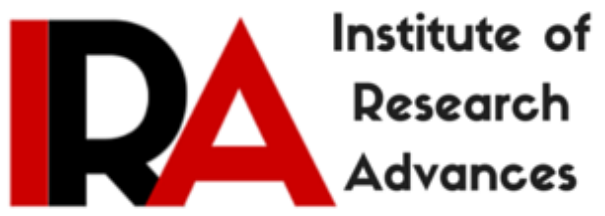

Advances

\title{
A Survey on the Usage of ICT in Pedagogy of Science
}

Dr Ritu Tripathi Chakravarty

Sr Assistant Professor, Amity Institute of Education, Amity University, Lucknow, India.

Type of Review: Peer Reviewed.

DOI: http://dx.doi.org/10.21013/jems.v7.n2.p8

How to cite this paper:

Chakravarty, R. (2017). A Survey on the Usage of ICT in Pedagogy of Science. IRA International Journal of Education and Multidisciplinary Studies (ISSN 2455-2526), 7(2), 109116. doi:http://dx.doi.org/10.21013/jems.v7.n2.p8

(C) Author.

\section{(cc) EY-NO}

This work is licensed under a Creative Commons Attribution-Non Commercial 4.0 International License subject to proper citation to the publication source of the work.

Disclaimer: The scholarly papers as reviewed and published by the Institute of Research Advances (IRA) are the views and opinions of their respective authors and are not the views or opinions of the IRA. The IRA disclaims of any harm or loss caused due to the published content to any party. 


\begin{abstract}
Information Communication Technology ICT has impacted the learning world. Educational systems have witnessed changes in the pedagogical approaches with the advent of ICT.

The survey of ten science teachers of ten different schools of Lucknow was done to the how ICT is being used as in the classroom pedagogy. The self prepare questionnaire was used. The data was collected from the science teachers. The findings are interesting. It was found that few science subjects the ICT and its applications are used optimally but some others were very less benefited by ICT. The findings also discusses the readiness of the science teachers for the usage of different types of ICT in teaching and management role in engaging and encouraging the opportunities for the usage of ICT in science teachings were explored.
\end{abstract}

\title{
Introduction
}

Technological progress, combined with a parallel evolution of pedagogical sciences, results in the belief that the integration of Information and Communication Technologies - ICT - into learning interaction may bring about a new era in the educational practice. However, the introduction of ICT in the educational practice is followed by essential gaps and encounters multifold difficulties. This fact turns ICT into a significant challenge for both the needs and the orientation of each and every educational system, imposing a complete review of their planning and organization, in order to make the transition to a new stage of systematic exploitation of technology possible. The use of ICT in education in most countries concentrates on routine type tasks, like sporadic and mechanical information retrieval from the internet. However, teachers and students have high expectation for using computers in their class rooms. This is because ICT can make science teaching and learning more versatile and goal oriented, motivate and activate students and promote cooperation, study in authentic context and creativity in learning.

ICT used in science education can

- make learning active, constructive, contextual, co-operative, self-regulated, reflective and cumulative and engages students in tackling the topic to be learnt in such a way that they create meaningful and understandable knowledge structure on the basis of a goal of learning.

- Increase interest, motivation and engagement in activities.

- Provide excess to resources (database, web page, videos, text, and demonstration) that are of high quality and relevant to learning.

- Enable visualisation, and manipulation of complex model and three dimensional images and movement to enhance scientific ideas.

- Supporting exploration and experimentation by providing immediate, visual feedback.

- Help students to learn to use ICT or increase their digital competence.

ICT offers also teachers opportunity to use tools application in preparing lessons to teach science.

\section{METHODOLOGY}

The survey was conducted in the form of a questionnaire which contained nine main closed ended questions. The first part contained information about the frequency of use of ICT for science teaching. The second part contained the use of ICT in which science subject the most. Third, fourth and fifth parts enquired about which technology is being used to teach Physics, Chemistry and Biology respectively. Each part asked about use of technologies like interactive board, video or audio clips, computer models, computer simulation and power point lecture presentation with options being used always, sometimes or never. The sixth part of the questionnaire gets information regarding which internet source the teacher refers to for content or refers to his/her students for further studies. The sub-parts of this main question has blogs, journals, e-books, science websites, online seminars, online forum and video conferences where options are always, sometimes or never. The seventh part enquires whether the teacher gives online assignments or holds online quizzes. The eighth part enquired about the obstacles the teacher faces in teaching science in her/his school like insufficient number of computers, insufficient internet bandwidth or speed, school time organization, lack of 
adequate skills of teachers, lack of adequate content/material for teaching, pressure to prepare students for exams and tests and that using ICT is not the goal of the school. The options in this section were a lot, somewhat or not at all. The last part asks about the positive impact of using ICT in science teaching. Students concentration more on what they are learning, achieving learning goals effectively, students understanding what is being taught easily, reduces work load, helps to grow in knowledge and improves the atmosphere are the fields asked with a lot, somewhat or not at all as the options.

Ten science pupil teachers were given one questionnaire each, to visit a school and ask its science teacher about the use of ICT in science teaching in the school. All the ten data obtained were tabulated and the cumulative analysis presented in the form of bar charts.

\section{Findings}

1. When investigated question on frequency of use Information and Communication Technology to teach science in Figure 1. ICT is used only once a week or twice a month in all the school. It was observed that six schools had ICT based lessons once a week and four schools had it twice a month. No school had lessons of blended learning every day.

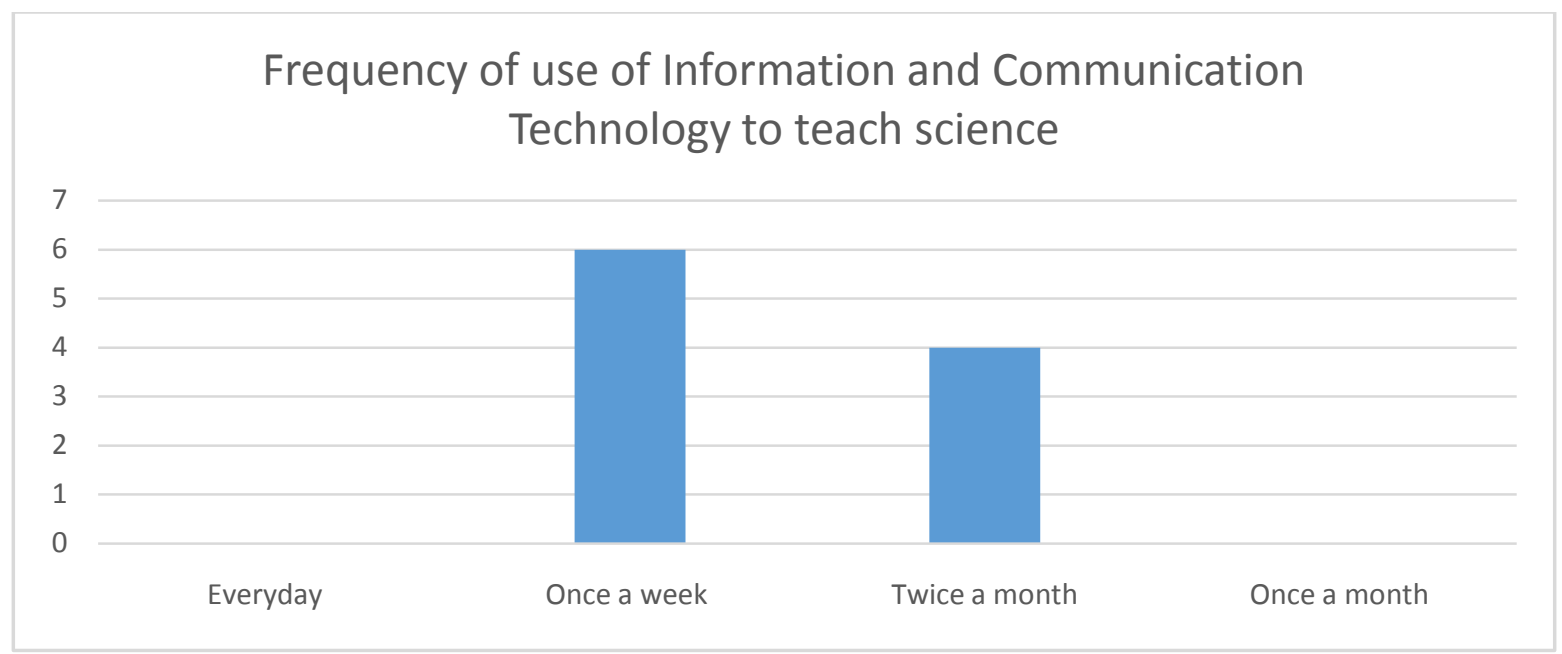

Figure 1.Frequency of use of Information and Communication Technology to teach science

Schools are yet to understand the benefits of blended learning and increase its frequency of use for science teaching. However, it was a relief to see at least schools do use it as rarely as once a month.

2. When Investigated on which science subject ICT was mostly incorporated the findings in Figure 2.are little discouraging for chemistry as subject few schools were restricted for the useage of ICT to teach chemistry..Although technology based teaching is shown for Physics and Biology, most of the schools use ICT in all of the subjects.

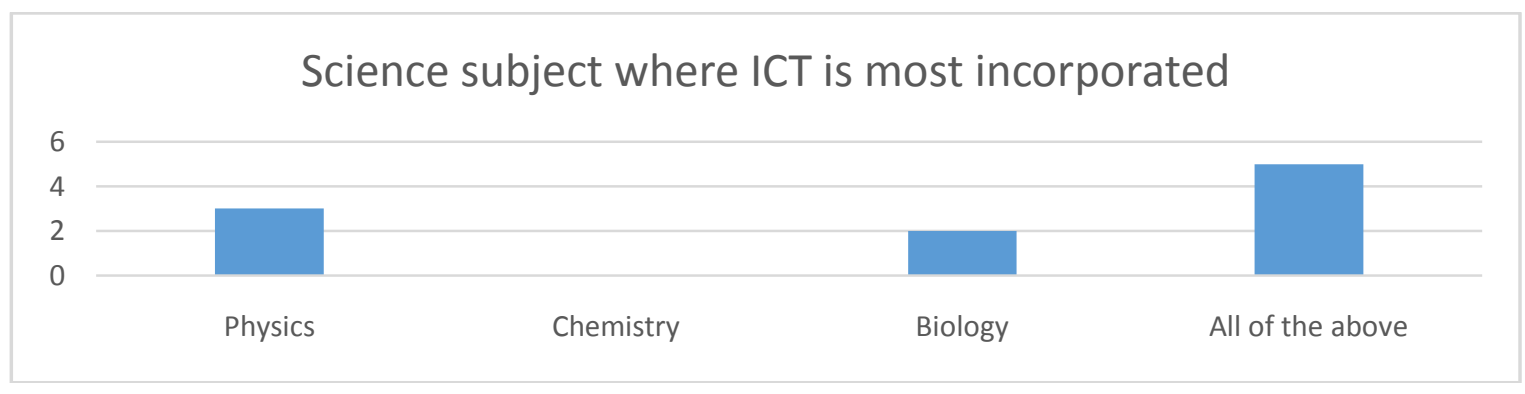

Figure 2.Science subject where ICT is most incorporated 
Five schools use ICT for all science subject where three use it for only Physics and two for only Biology.

3. Concerning what types of ICT the science teacher teaching Physcis uses Figure 3 . shows that Interactive board was used sometimes by six schools to teach Physics, three used it always while only one school never used it for Physics. Video/audio clips were used by four schools always, three schools sometimes and three schools never for teaching Physics to students. Computer models were used by six schools soometimes, three schools never and one school always for Physics lectures.

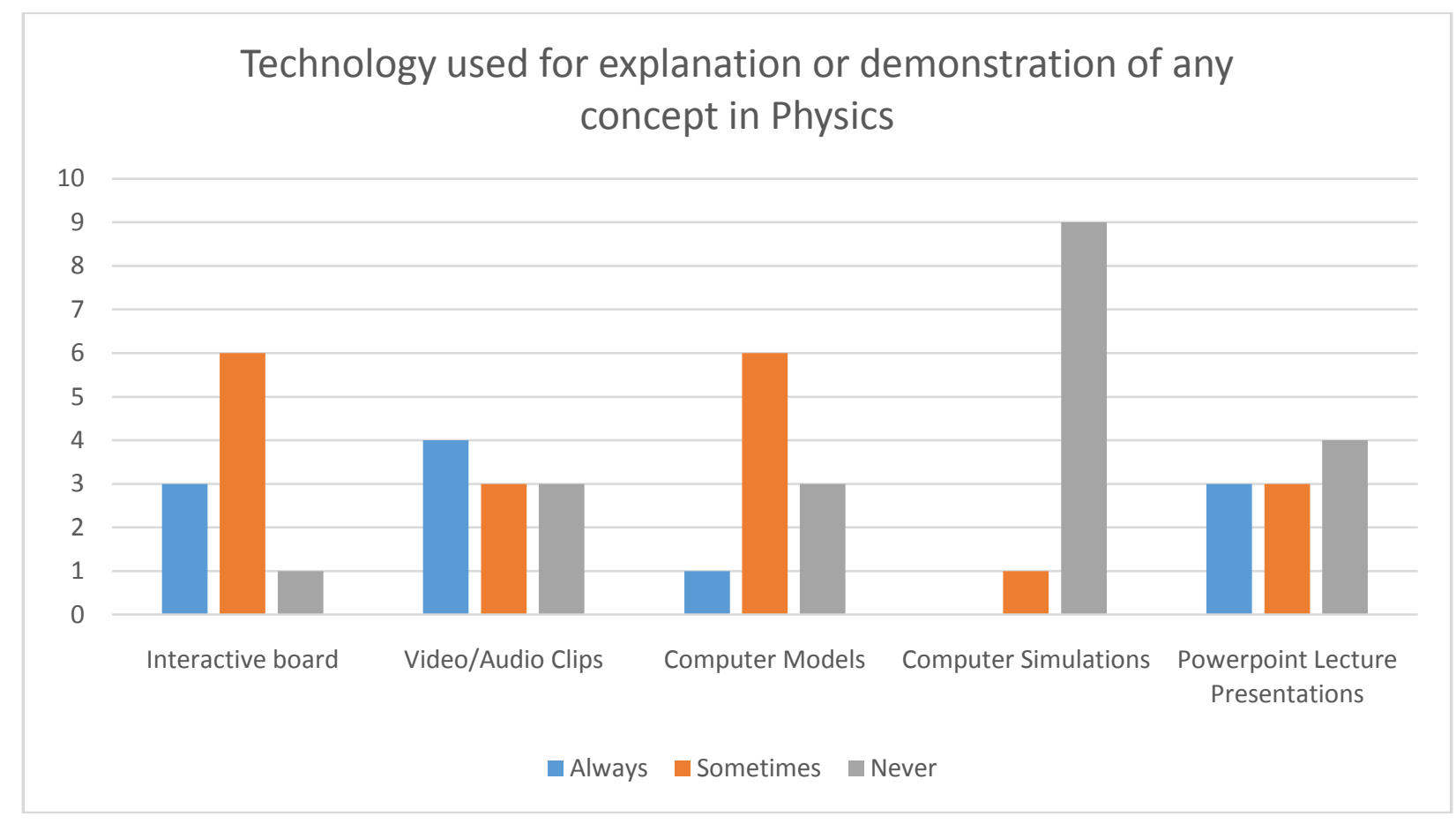

Figure 3.Technology used for explanation or demonstration of any concept in Physics

Computer simulations are never used by nine schools and only one school used it for teaching Physics concepts. This was mainly because interactive boards usually provide all necessary effects and an additional software for simulations was not felt necessary. Mostly, the power point lecture presentation was never employed (four schools) for teaching Physics but threeschools use it sometimes and three always.

4. When it comes to the useage of ICT in chemistry Figure 4 shows that Interactive board was used sometimes by four schools to teach Chemistry, four that use always while only two school never used it for Chemistry. Video/audio clips were used by four schools always, four schools sometimes and two schools never for teaching Chemistry to students. Computer models were used by six schools soometimes, two schools never and two schools always for Chemistry lectures. 


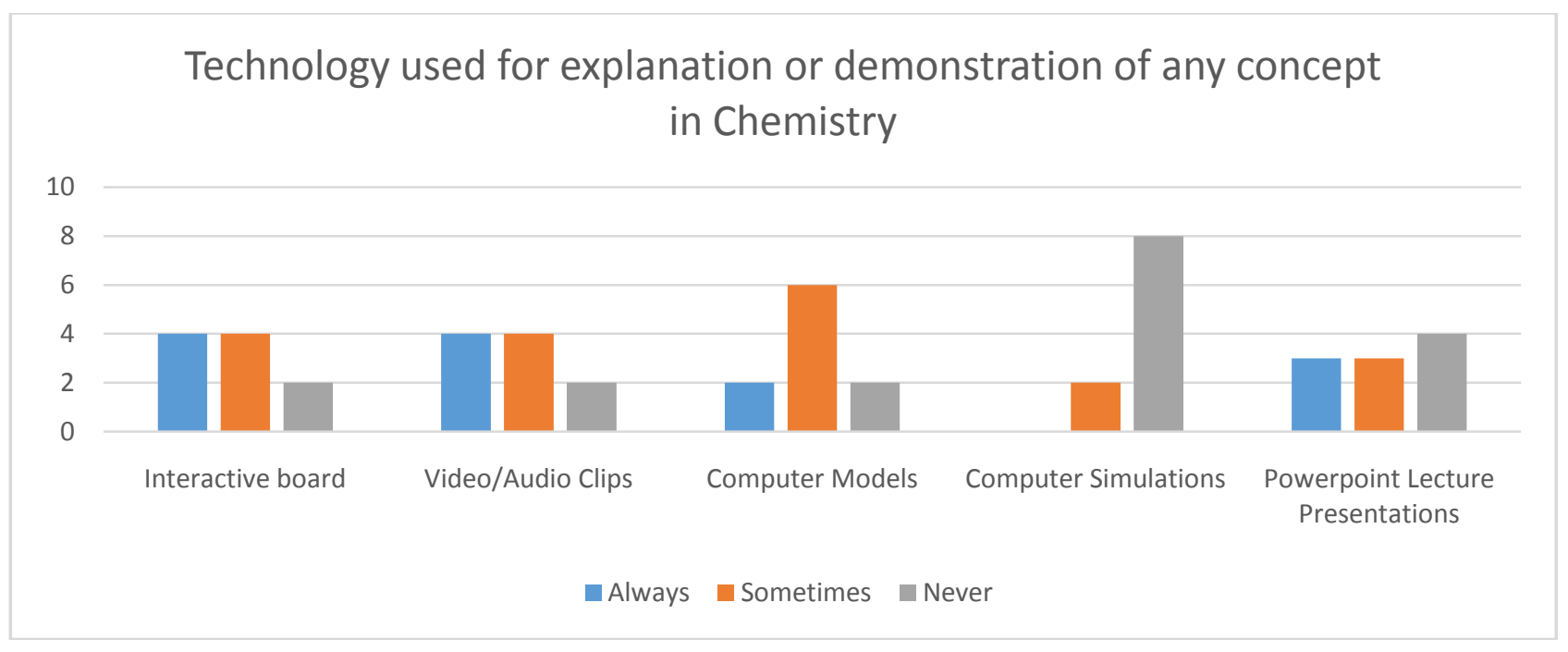

Figure 4.Technology used for explanation or demonstration of any concept in Chemistry

Computer simulations are never used by eight schools and only two schools used it for teaching concepts of Chemistry. This was mainly because interactive boards usually provide all necessary effects and an additional software for simulations was not felt necessary. Mostly, the power point lecture presentation was never employed (four schools) for teaching Chemistry but two schools use it sometimes and two always.

5.Interactive board was used sometimes by six schools to teach Biology, two that use always while only two school never used it for Biology. Video/audio clips were used by five schools sometimes, four schools always and one school never for teaching Biology to students. Computer models were used by four schools never, three schools always and three schools sometimes for Biology lectures.

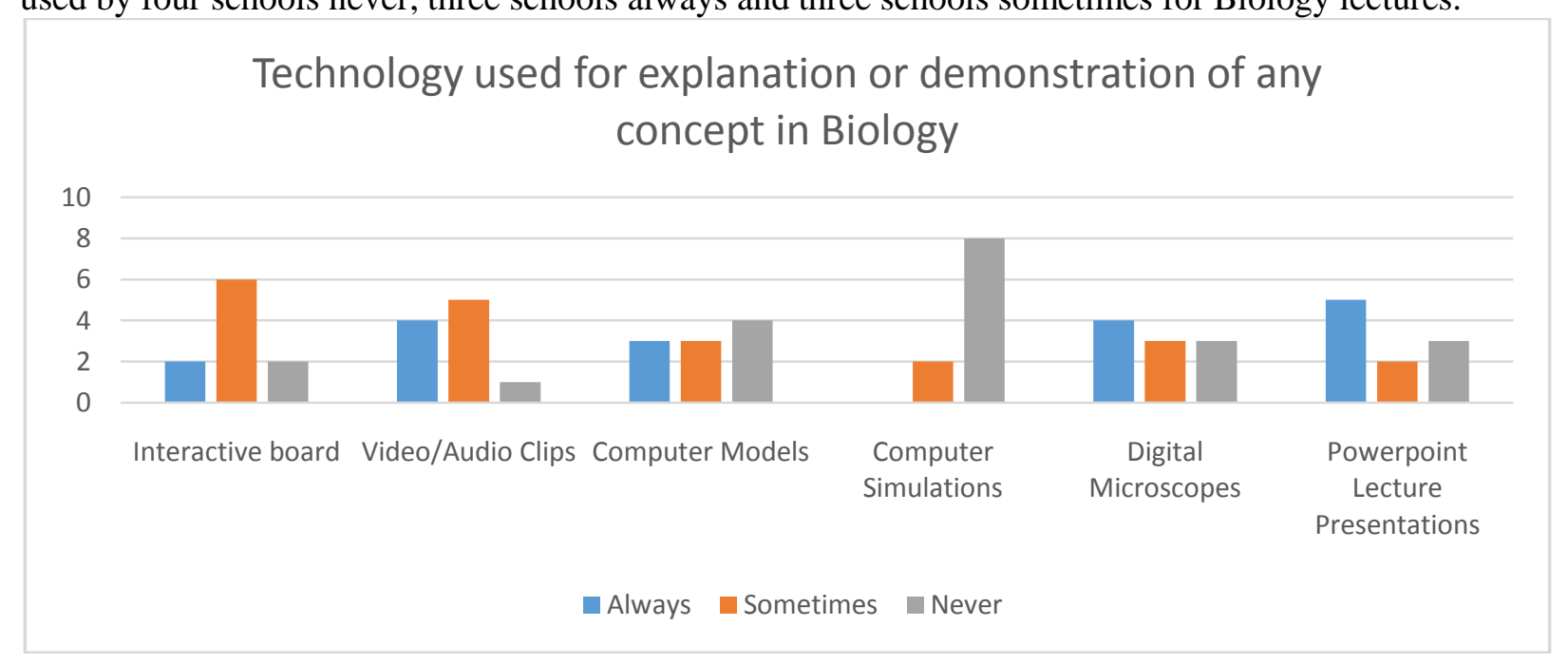

Figure 5.Technology used for explanation or demonstration of any concept in Biology

Computer simulations are never used by eight schools and only two schools used it for teaching concepts of Biology. Digital microscopes were used always by four schools, sometimes by three schools and never by three schools in Biology. Power point lecture presentation was used always by five schools, three schools never and only two used it sometimes to teach Biology. 
6. Figure 5 shows the different sources science teacher use for the refernce and it was found out that six teachers referred to Science Blogs, three never referred it and only one referred to it always for content or to students for further studies. Five teachers referred to Journals online, four never and only one always for content. All interviewed teachers used ebooks for content or referred to students for further studies. Mostly teachers visited Science websites always while only four referred to them sometimes. Six teachers never participated in online seminars and four took part sometimes. Five teachers sometimes participated in online forum and the other five never did any discussion online.

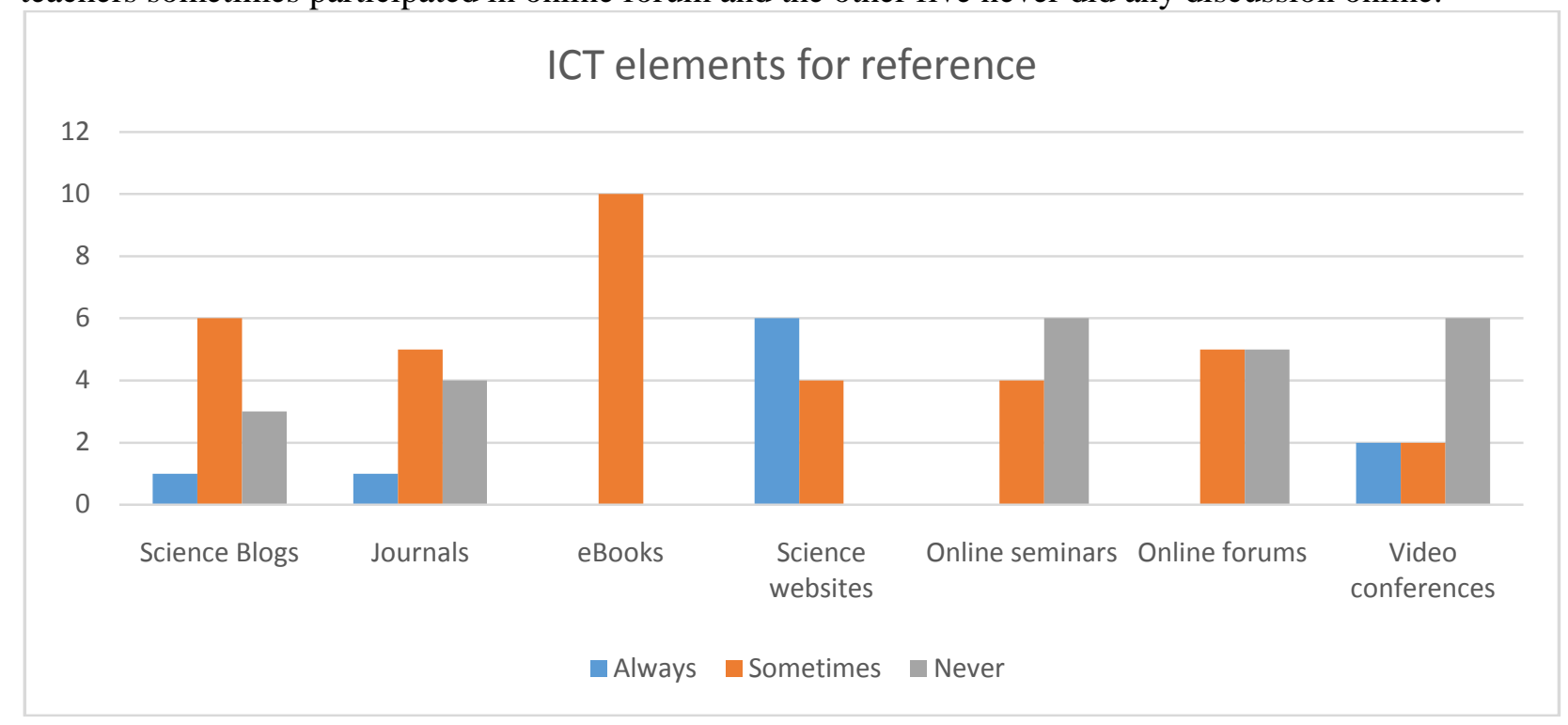

Figure 6 .ICT elements for reference

Video conferences were never an option for six, however, two used is sometimes and two used it always for increasing content knowledge. Teachers are yet not participatory in online discussions on science related topics because of lack of awareness and lack of time.

7.Seven teachers opt for Online Assignments as a method of asssessment. As figure 7 shows the online assignments is very popularly used in science teaching. Two teachers never give online asssignments and only one teacher always gives it for assessment purpose

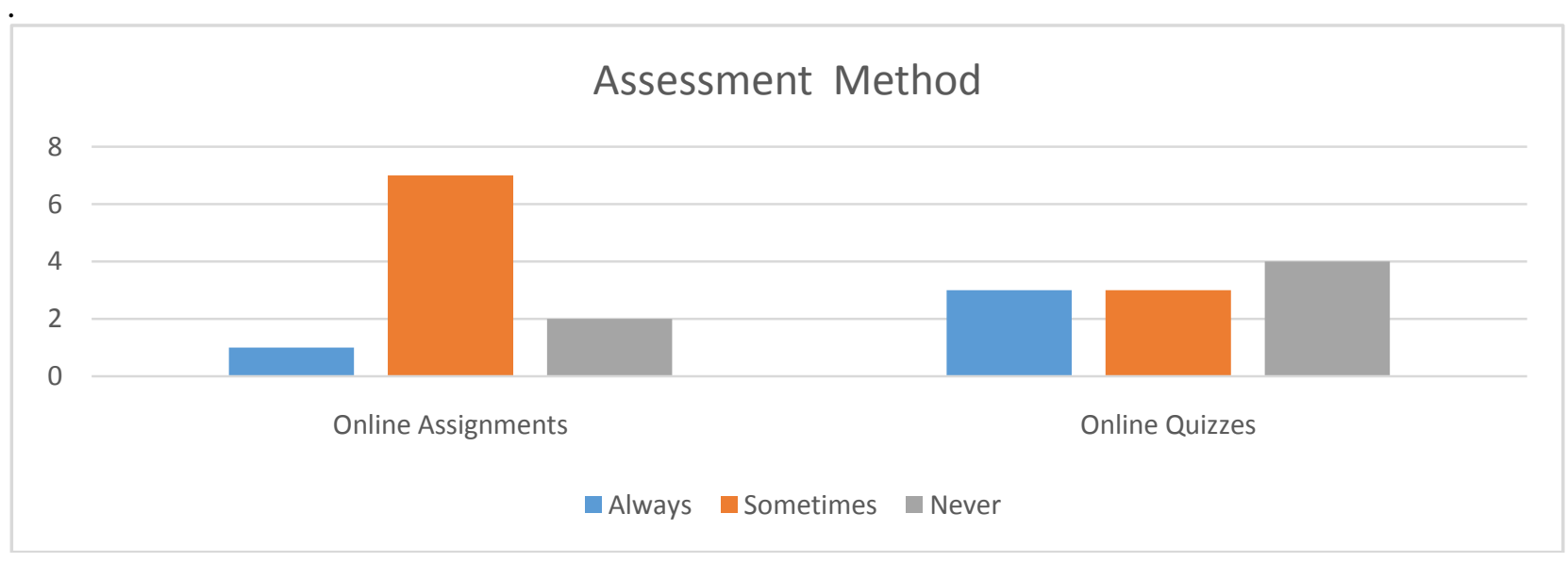

Figure 7.Assessment Method

Online Quizzes are never used by four teachers whereas three teachers use them always and three teachers use them sometimes as assessment method.It shows that online method of assessment are gaining popularity amongst the science teachers 
8. In figure 8 obstacles met during the usage of ICT are investigated. Seven teachers, somewhat, faced problem of insufficient computers in teaching science through ICT in their school and three teachers faced no such problem. Insufficient internet speed is sometimes the problem of five schools, three schools have a lot of this problem. However, only two schools do not have insufficient bandwidth as a problem for teaching science through ICT. School time organization e.g. fixed lesson time is somewhat a problem for seven schools whereas three say that it causes a lot of problem. Five teachers say that lack of adequate skills somewhat becomes an obstacle for teaching science through ICT but four say that that is not a problem at all. However, only one teacher said that inadequate skills is a lot of problem for ICT science teaching. Lack of adequate content not an obstacle for five teachers whereas five state that it is somewhat a problem for ICT based teaching of science

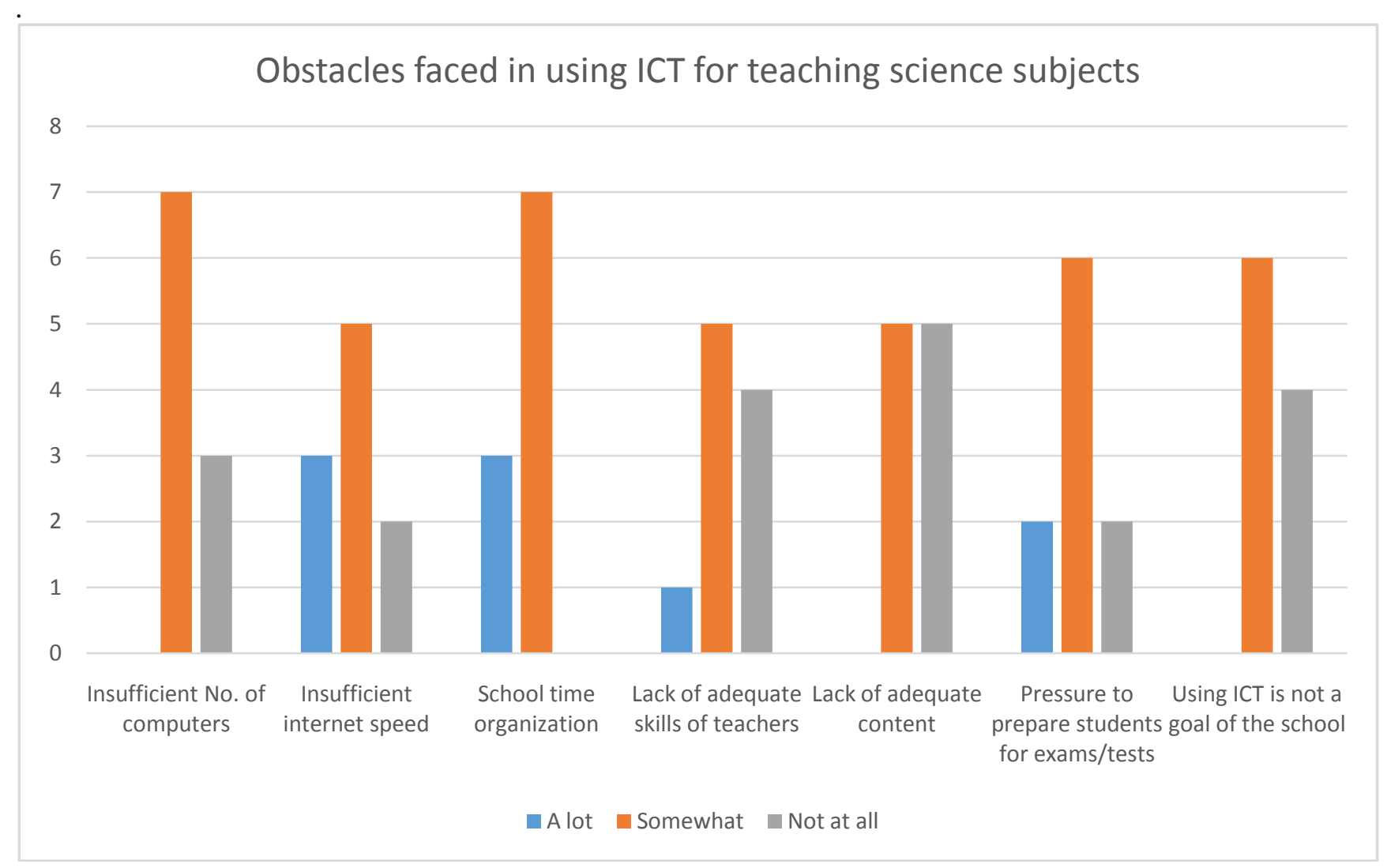

Figure 8.Obstacles faced in using ICT for teaching science subjects

Six teachers consider the pressure on them to prepare students for exams as somewhat an obstacle while two state that that is a lot of problem and two say that is not a problem at all for teaching science subjects through ICT. Six teachers opinioned that using ICT geing not the goal of the school somewhat acts as an obstacle towards science teaching while four say that that is not a problem at all.

9. It shows in figure 9 that eight teachers believe that students concentrate a lot when using ICT for science lessons and only two said that they somewhat concentrate more. Five teachers observed that they always achieve the learning goals effectivley while five think that the learning goals are somewhat achieved when using ICT during science lessons. Students always understand easily is said by six teachers whereas four teachers they somewhat understand easily through ICT based teaching. 


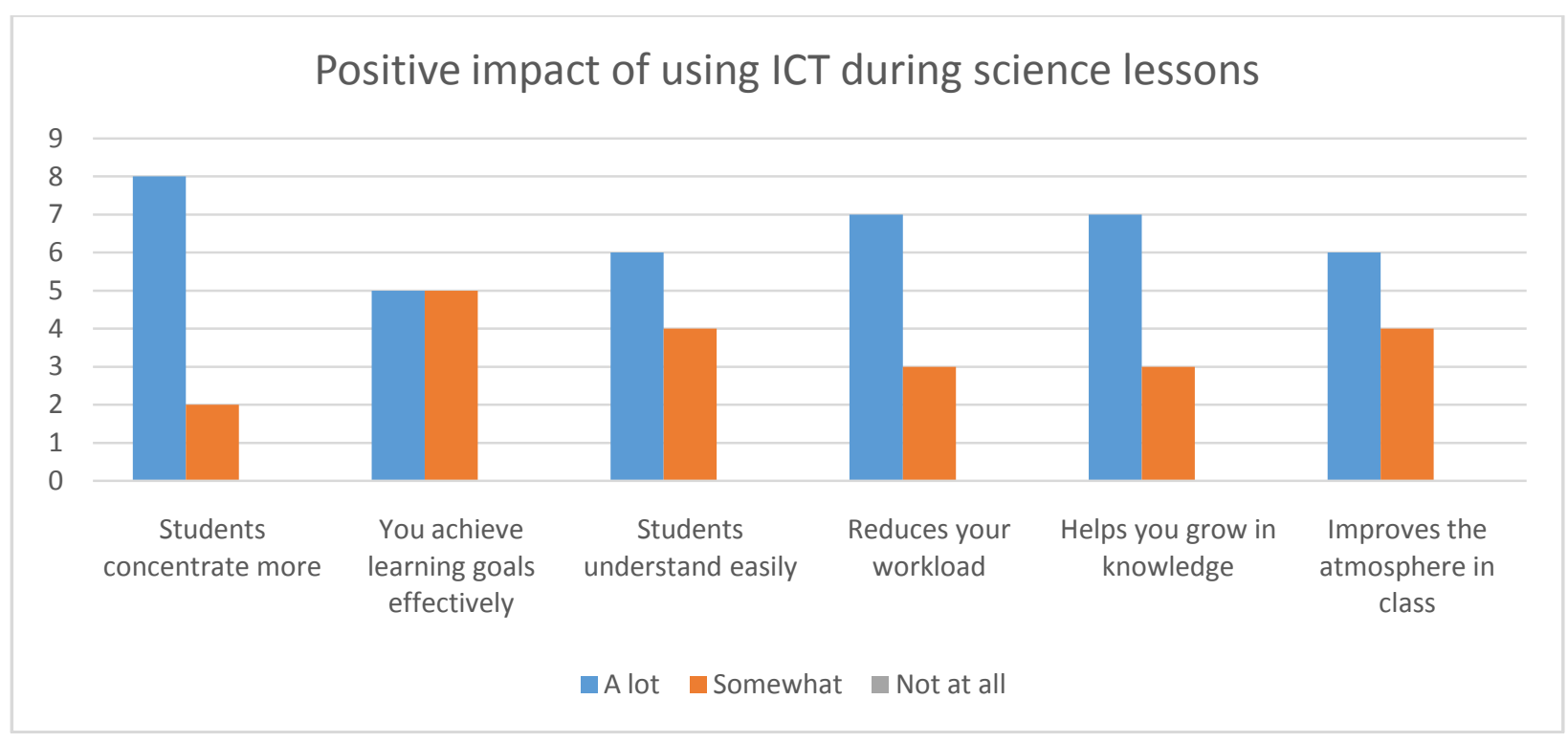

Figure 9. Positive impact of using ICT during science lessons

Seven teacher admitted that ICT usage for science lessons reduces their work load and helps them grow in knowledge a lot and three said that it somewhat reduces their work load and somwhat helps them gain content knowledge. Six teachers think that using ICT during science lessons inmproves the atmosphere of the class a lot while four think that it somewhat improves the class atmosphere.

\section{CONCLUSION}

The use of Information and Communication Technology in science education is still occasional and limited. Almost all of the science subjects are taught by one means or the other of ICT. However, interactive boards are the most prevalent ICT media which have limited the use of other types of ICT elements as it is quite complete and contains adequate content to teach the required science subjects. Although science teachers are not aware of the various internet sources that they can refer themselves or recommend it to their students for further studies they do consult the internet to update themselves in their field frequently. ICT based assessment methods have been adopted well with open arms by teachers of nowadays. Despite all the enthusiasm about the positive impact of about blended learning, there are still various obstacles faced by schools and/or teachers in implementing ICT in their everyday curriculum. In order to increase the usage of ICT in teaching and to make ICT as an Inseparable Pedagogy the whole educational systems needs to be exposes to the benefits of ICT .The government should promote the usage by providing the services at minimum cost, the management should make ICT as a Important agenda in the vision and mission of the school. Teacher should imbibe all the qualities required for the usage and promotion of the ICT and students should access and enhance their knowledge with various available ICT as their young minds have immense hunger for new knowledge and creativity for their holistic development.

\section{References}

1. Amajuoyi, J.J. (2012). Towards effective integration of information and communication technology in universal basic education: issues and challenges to ST in education journal of 52 annual conference of science teachers association of Nigeria 2012. HEBN publishers plc

2. BROWN, D., HARPER, E., 2003.'A twenty-first century science laboratory.' School Science Review, 84 (309), pp. 87-91.

3. Liverpool E. Onyije, Jacinta A. Opara, International Letters of Social and Humanistic Sciences 1 (2014) 81-87

4. www.ase.org.uk/resource/scitutor

5. http://www.fizyka.umk.pl/ pdf/EU_ISE/files/new/EUISEBookHR.pdf

6. http://archive.futurelab.org.uk/resources/publications-reports-articles/literature-reviews/LiteratureReview380 